\title{
Layer-By-Layer Fabrication of Large and Thick Human Cardiac Muscle Patch Constructs With Superior Electrophysiological Properties
}

\author{
Danielle Pretoriuss ${ }^{1}$, Asher M. Kahn-Krell' ${ }^{1}$ Xi Lou' ${ }^{1}$, Vladimir G. Fast ${ }^{1}$, Joel L. Berry ${ }^{1}$, \\ Timothy J. Kamp ${ }^{2}$ and Jianyi Zhang ${ }^{1 *}$ \\ ${ }^{1}$ Department of Biomedical Engineering, School of Medicine and School of Engineering, University of Alabama \\ at Birmingham, Birmingham, AL, United States, ${ }^{2}$ Department of Cell and Regenerative Biology, University \\ of Wisconsin-Madison, Madison, WI, United States
}

\section{OPEN ACCESS}

Edited by:

Shijun Hu,

Soochow University, China

Reviewed by: Zhen Ma,

Syracuse University, United States Ke Cheng,

University of North Carolina Hospitals,

United States

*Correspondence:

Jianyi Zhang

jayzhang@uab.edu

Specialty section:

This article was submitted to

Stem Cell Research,

a section of the journal

Frontiers in Cell and Developmental

Biology

Received: 21 February 2021

Accepted: 29 March 2021

Published: 16 April 2021

Citation:

Pretorius D, Kahn-Krell AM, Lou X, Fast VG, Berry JL, Kamp TJ and Zhang J (2021) Layer-By-Layer

Fabrication of Large and Thick Human Cardiac Muscle Patch Constructs With Superior Electrophysiological

Properties.

Front. Cell Dev. Biol. 9:670504. doi: 10.3389/fcell.2021.670504
Engineered cardiac tissues fabricated from human induced pluripotent stem cells (hiPSCs) show promise for ameliorating damage from myocardial infarction, while also restoring function to the damaged left ventricular (LV) myocardium. For these constructs to reach their clinical potential, they need to be of a clinically relevant volume and thickness, and capable of generating synchronous and forceful contraction to assist the pumping action of the recipient heart. Design prerequisites include a structure thickness sufficient to produce a beneficial contractile force, prevascularization to overcome diffusion limitations and sufficient structural development to allow for maximal cell communication. Previous attempts to meet these prerequisites have been hindered by lack of oxygen and nutrient transport due to diffusion limits (100-200 $\mu \mathrm{m})$ resulting in necrosis. This study employs a layer-by-layer $(\mathrm{LbL})$ fabrication method to produce cardiac tissue constructs that meet these design prerequisites and mimic normal myocardium in form and function. Thick (>2 mm) cardiac tissues created from hiPSCderived cardiomyocytes, -endothelial cells (ECs) and -fibroblasts (FBs) were assessed, in vitro, over a 4 -week period for viability ( $<6 \%$ necrotic cells), cell morphology and functionality. Functional performance assessment showed enhanced $t$-tubule network development, gap junction communication as well as previously unseen, physiologically relevant conduction velocities $(\mathrm{CVs})(>30 \mathrm{~cm} / \mathrm{s})$. These results demonstrate that LbL fabrication can be utilized successfully to create prevascularized, functional cardiac tissue constructs from hiPSCs for potential therapeutic applications.

Keywords: hearts, tissue engineering, layer-by-layer fabrication, stem cell, superior electrophysiology

\section{INTRODUCTION}

The use of engineered cardiac muscle patch constructs focusing on repair and functional restoration following an acute myocardial infarction (AMI), have shown promise in improving clinical outcomes for patients (Lake et al., 1985; Lucas and Szweda, 1999; Murphy and Steenbergen, 2008). Clinically, AMI is associated with postinfarction left ventricular (LV) remodeling and heart failure (Henkel et al., 2006; Gorenek et al., 2014). Cell therapy approaches utilizing products associated with human induced pluripotent stem cells (hiPSCs) have been examined pre-clinically as a viable therapeutic option (Xiaojun et al., 2012, 2014; Ye et al., 2014). Despite these promising results, the 
search continues for an effective method of restoring both mechanical and electrical function to the AMI damaged region of the heart, which is necessary for a successful therapeutic application. Furthermore, electrical function is largely dependent upon the electrical excitability of the cells and subsequently the engineered tissue. Unfortunately, due to their immature phenotype, hiPSC-derived cardiomyocytes (iCMs) tend to have reduced electrical excitability compared to mature, adult CMs found in the native myocardium (O'Hara et al., 2011; Mummery et al., 2012).

One of the key indicators for CM functional maturity at the tissue level is the capacity to support fast action potential (AP) conduction. In cardiac tissue, AP represents the timedependent changes in the transmembrane electrical potential in CMs, which occur during each heartbeat, and are functions of highly coordinated, time- and voltage-dependent changes in activity of various ion channels and transporters (Liu et al., 2016). Conduction velocities (CVs) of genetically purified iCMs in monolayer format have been reported as high as $\sim 21 \mathrm{~cm} / \mathrm{s}$ (Lee et al., 2012), with more complex 3D systems still lagging behind at reported CVs around 14-17 cm/s (Gao et al., 2018; Pretorius et al., 2020) with the potential of reaching up to $25 \mathrm{~cm} / \mathrm{s}$ when highly organized (Gao et al., 2017). However, promising, the CVs reported for hiPSC-derived tissue still fall short of those observed in native adult LV tissue $(\sim 30-100 \mathrm{~cm} / \mathrm{s}$; Valderrábano, 2007; Yang et al., 2014). Some of the highest CVs reported for engineered cardiac tissue have been obtained with neonatal rat CMs, and was recorded at $32.3 \pm 1.8 \mathrm{~cm} / \mathrm{s}$, yet at their thickest, these structures were recorded to only be $100 \mu \mathrm{m}$ (Jackman et al., 2018).

Utilization of promising fabrication strategies which yield highly organized structures, such as the layer-by-layer (LbL) approach, allow for superior control over a range of physicochemical properties. In a previous study, we demonstrated that our LbL fabrication method yields thick, vascularized engineered cardiac tissue, with CVs ranging between 17 and $19 \mathrm{~cm} / \mathrm{s}$, as well as viscoelastic properties that were similar to native murine myocardial tissue (Pretorius et al., 2020), yet this study only utilized CMs and endothelial cells (ECs). It is known, however, that fibroblasts (FBs) play key roles in the healthy native adult mammalian heart. FBs contribute to general heart function, homeostasis, and structure, most notably during the production and remodeling of extracellular matrix (ECM). Culturing CMs in the presence of FBs has also been shown to affect the electrophysiological properties of the CMs (Zhang et al., 2019).

In the present study, we aimed at developing a LbL approach to engineer large and thick tri-lineage (CM, EC, and FB) cardiac tissue constructs. The engineered cardiac tissue was characterized at various time points, over a 4 week period, in order to qualify and quantify the changes that occur in the structures in vitro, which ultimately lead to a better potential understanding of the remodeling that these structures undergo in vivo. We hypothesized that by mimicking the cellular composition of the native myocardium, i.e., utilizing CMs, ECs, and FBs, with a LbL fabrication process would not only allow for the production of thicker tissues but also increase their ability to mimic the native myocardium more closely in terms of form and function. Characterization included (1) histology and immunostaining to analyze the cellular and structural morphology, (2) immunostaining to quantify viability, (3) immunostaining of $2 \mathrm{D}$ cryosections and $3 \mathrm{D}$ structures to analyze cell migration, potential vascularization, and final cellular fate, (4) immunostaining and quantification of ECM remodeling, (5) RNA analysis to quantify and corroborate the results obtained from immunostaining, and (6) optical mapping to determine the $\mathrm{AP}$ and $\mathrm{CV}$ to assess functionality.

\section{MATERIALS AND METHODS}

\section{Cell Culture and Characterization}

Human cardiac fibroblast induced pluripotent stem cells were reprogrammed from human cardiac FBs, and subsequently differentiated into hiPSC-cardiomyocytes (iCMs), as previously reported (Lian et al., 2012; Burridge et al., 2014; Ye et al., 2014). Generally, spontaneous iCM contractions were observed between days 7 and 10 after commencement of the differentiation protocol, with beating numbers increasing up to day 12 . Metabolic purification of iCMs was achieved via glucose deprivation (RPMI 1640 without glucose, supplemented with sodium DL-lactate and $\mathrm{B} 27^{+}$, Gibco) for 3-6 days, initiated at day 9, allowed for a population of iCMs that yielded a minimum of $95 \%$ cTnT positive. hiPSCs were maintained at optimal conditions, as previously described (Zhu et al., 2017), on six-well plates coated with Matrigel (Corning), using mTeSR 1 maintenance media (STEMCell Technologies, Canada).

Human induced pluripotent stem cell-endothelial cells (iECs) were differentiated as described previously (Zhang et al., 2014; Gao et al., 2018; Su et al., 2018). Briefly, undifferentiated hiPSCs were seeded into $0.5 \mathrm{~mL}$ fibrin scaffolds and treated with CHIR99021 and U46619 in EBM2 medium (Lonza, United States) supplemented with B27- for $24 \mathrm{~h}$. The medium was then replaced with EBM2 which was supplemented with $\mathrm{B}^{2} 7^{-}$, vascular endothelial growth factor (VEGF), erythropoietin (EPO), and transforming growth factor $\beta 1$ (TGF $\beta 1$ ), and then cultured for an additional $96 \mathrm{~h}$ with a media change midway through. Finally, the scaffolds were released and cultured in EGM2-MV medium (Lonza, United States) supplemented with $\mathrm{B}^{+} 7^{+}$, VEGF, and SB-431542, with media changes every 2 days. hiPSC-ECs were purified and enriched via collection of cells positive for CD31 using fluorescence-activated cell sorting (FACSAria II). Antibodies used for selection and cell characterization are listed Supplementary Table 1. See Supplementary Figure $\mathbf{1}$ for cell characterization and Supplementary Figure $\mathbf{2}$ for the proliferation assay showing the lack of tumorigenic properties of the iCMs utilized in this study.

Human induced pluripotent stem cell-FB ( $\mathrm{cFB}$ ) differentiation commenced using hiPSC-line DF19-9-11T with cells at 100\% confluence (day 0) (Zhang et al., 2019). The hiPSC culture medium was changed to RPMI/B27 ${ }^{-}$and supplemented with $12 \mu \mathrm{M}$ CHIR99021, with cells treated in this medium for $24 \mathrm{~h}$ (day 1). Medium was changed once again to RPMI/B27 ${ }^{-}$for another $24 \mathrm{~h}$ (day 2). Within $24 \mathrm{~h}$ (before day 3), the medium 
was changed to cardiac FB differentiation basal medium (CFBM, see Supplementary Table 2) supplemented with $75 \mathrm{ng} / \mathrm{mL}$ bFGF (WiCell Research Institute). Cells were then cultured with CFBM $+75 \mathrm{ng} / \mathrm{mL}$ bFGF every other day up to day 20 when they were utilized for flow cytometry analysis and passaged for subsequent use in tissue fabrication.

\section{Fibrin Matrix Composition}

The fibrin matrix used (per milliliter) used for the differentiation of the iECs as well as for the construction of each alternating layer of the cardiac tissue during the modular fabrication process consisted of the following components as was defined previously (Gao et al., 2018): $0.12 \mathrm{~mL}$ fibrinogen ( $25 \mathrm{mg} / \mathrm{mL}$, Sigma-Aldrich, CAS\# 9001-32-5), 0.02 mL Matrigel (Corning, \# 356235), $0.56 \mathrm{~mL}$ of HEPES (20 mM, pH 7.4, Corning), $0.001 \mathrm{~mL} \mathrm{CaCl}_{2}(2 \mathrm{M})$, $0.3 \mathrm{~mL}$ DMEM (Gibco, High glucose, \# 11965-118), and $0.006 \mathrm{~mL}$ thrombin (80 U/mL, MP Biomedicals).

\section{Polydimethylsiloxane Platforms}

Polydimethylsiloxane (PDMS) platforms were fabricated by mixing PDMS (Dow Corning Sylgard 184 Silicone, Product \#2065622) in a 10:1 elastomer:curing agent ratio and poured into a $100 \mathrm{~mm}$ diameter Pyrex Petri dish (Corning, \# 3160102). These were cured at $75^{\circ} \mathrm{C}$ for $2 \mathrm{~h}$ in an oven, after which custom platforms of $10 \mathrm{~mm} \times 5 \mathrm{~mm}$ (2.5 mm thick) were cut. Prior to their use in the tissue fabrication and culture process, all PDMS structures were autoclaved.

\section{Optimized LbL Engineered Tissue Fabrication}

Following cell differentiation, cardiac tissue fabrication commenced (Figure 1). Petri dishes (BioLite Cell Culture Treated Dishes, Thermo Scientific) were coated with a 5\% pluronic F-68 solution (Gibco, \# 24040032) and incubated at $4^{\circ} \mathrm{C}$ overnight. The pluronic solution was removed, and a sterile polycarbonate frame (internal area: $1 \times 2 \mathrm{~cm}^{2}$ ) was attached with a $2 \%$ agarose solution. Note that the frames were modified with channels to allow for maximal media contact following tissue fabrication. iCMs were dissociated (STEMdiff Cardiomyocyte Dissociation Medium, STEMCell) and mixed with the fibrin matrix at a concentration of $10 \times 10^{6}$ cells $/ \mathrm{mL}$. Note that the deposition of the iCM layer denotes "D0" for the remainder of the fabrication process. $400 \mu \mathrm{L}$ of this solution was quickly deposited into each mold to produce the first layer. Following complete polymerization, the culture medium was added (STEMdiff Cardiomyocyte Support Medium, $2 \mathrm{mg} / \mathrm{mL}$ $\varepsilon$-aminocaproic acid) and incubated at $37^{\circ} \mathrm{C}\left(5 \% \mathrm{CO}_{2}\right)$ for 2 days. The next layer, comprised of iECs, was made in a similar fashion, with the following exceptions: iECs were dissociated using trypsin (0.25\% trypsin, 0.1\% EDTA, Corning, \# 25053CI) and then mixed with the fibrin matrix at a concentration of $10 \times 10^{6}$ cells $/ \mathrm{mL}$. $200 \mu \mathrm{L}$ of this solution was quickly deposited into each mold, yielding a 2:1 ratio of iCMs:iECs (Gao et al., 2018). Fresh culture medium (10\% fetal bovine serum, $2 \% \mathrm{~B} 27^{+}$, and $2 \mathrm{mg} / \mathrm{mL} \varepsilon$-aminocaproic acid, $10 \mu \mathrm{M}$ ROCK inhibitor in DMEM) was added, following layer polymerization. After
$24 \mathrm{~h}$, the frame containing the engineered cardiac tissue was lifted off of the dish surface and placed on top of custom-cut PDMS stilts, allowing for the tissue to be fully suspended in fresh culture media ( $2 \%$ fetal bovine serum, $2 \% \mathrm{~B} 27^{+}$, and $2 \mathrm{mg} / \mathrm{mL}$ $\varepsilon$-aminocaproic acid in DMEM). After a further $48 \mathrm{~h}$, the next layer, comprised of $\mathrm{cFBs}$, was made in a similar fashion, with the following exceptions: cFBs were dissociated using TrypLE (Gibco, \# 12604013) and then mixed with the fibrin matrix at a concentration of $10 \times 10^{6}$ cells $/ \mathrm{mL} .100 \mu \mathrm{L}$ of this solution was quickly deposited into each mold, yielding a 2:1:0.5 ratio of iCMs:iECs:cFBs (Pinto et al., 2016; Gao et al., 2018). Incubation continued for the desired period of time (1-4 weeks in total), with media replacement once per week.

\section{Tissue Preservation}

Fabricated tissue samples were fixed in 4\% formaldehyde (Pierce, Thermo Scientific, \# 28906) for $1 \mathrm{~h}$ prior to embedding in either optimal cutting temperature compound (OCT compound, Fisher Health Care, United States) or paraffin for histological analysis. Histological analyses were performed on $10 \mu \mathrm{m}$ sections. Wholemount samples were stored in PBS until staining.

\section{Histochemistry}

Deparaffinized and rehydrated sections were stained with hematoxylin solution (Mayer's, Merck, $3 \mathrm{~min}$ ) followed by working eosin $\mathrm{Y}$ solution $(2 \mathrm{~min})$. Following subsequent dehydration, all samples were mounted with Permount and imaged using a bright field microscope (Olympus IX83 epifluorescent microscope).

\section{Immunohistochemistry}

Fixed OCT embedded sections were blocked and permeabilized for $30 \mathrm{~min}$ in $10 \%$ donkey serum, 3\% BSA, and $0.05 \%$ Triton$\mathrm{X}$. Following addition of primary antibodies, samples were incubated for $1 \mathrm{~h}$ at room temperature (Supplementary Table 1). Samples were washed in PBS $(3 \times 5 \mathrm{~min})$, and subsequently labeled with secondary antibodies with fluorescent tags and $4^{\prime}$, 6-diamidino-2-phenylindole (DAPI, $100 \mathrm{ng} / \mathrm{mL}$ ) and incubated for at room temperature for $1 \mathrm{~h}$ (Supplementary Table 1). Sections were mounted with VECTASHIELD Antifade Mounting Medium and visualized by confocal laser scanning (Olympus FV3000 confocal microscope).

\section{Whole-Mount Staining}

Fixed whole-mount samples were blocked and permeabilized in $10 \%$ donkey serum, $10 \%$ Tween- $20,3 \%$ BSA, $0.05 \%$ Triton$\mathrm{X}$, and $0.02 \%$ sodium azide in PBS overnight at $4^{\circ} \mathrm{C}$. Then, primary antibodies were added and samples were incubated overnight at $4^{\circ} \mathrm{C}$ (Supplementary Table 1). Samples were washed in $\operatorname{PBST}(3 \times 10 \mathrm{~min})$ and fluorescently labeled secondary antibodies along with DAPI were added followed by another overnight incubation at $4^{\circ} \mathrm{C}$. Following washing, tissue was cleared according to the previously described protocol ( $\mathrm{Li}$ et al., 2019) with $3 \mathrm{~h}$ incubation in Ce3D clearing agent. Wholemount constructs were transferred to an Ibidi $\mu$-Slide (\# 80286), covered with VECTASHIELD Antifade Mounting Medium, 


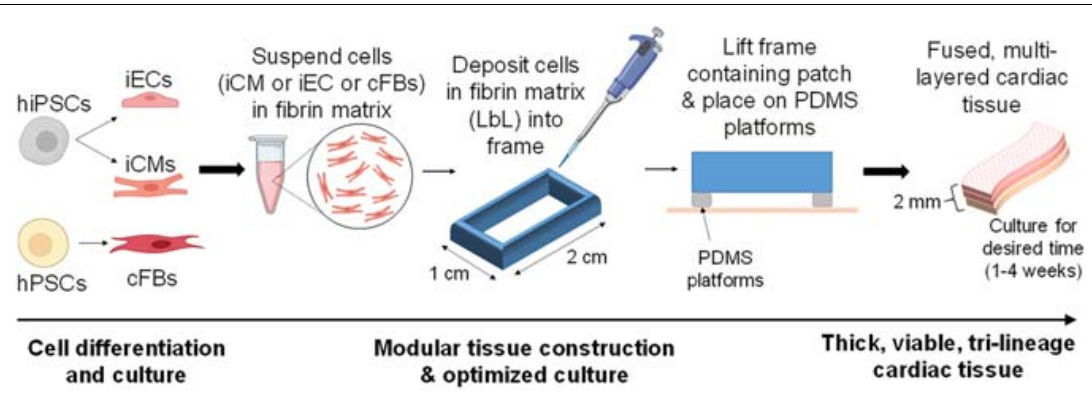

FIGURE 1 | Basic description of optimized cardiac tissue surrogate fabrication process, allowing for extended culturing of thick tissue structures. The first layer of cells is deposited and cultured for $48 \mathrm{~h}$, after which the second layer is deposited using layer-by-layer (LbL) approach. The second layer of cells is deposited, allowed to polymerize, and the entire structure contained in its frame is then lifted off of the dish surface and placed on top of Polydimethylsiloxane (PDMS) platforms. The third layer of cells is deposited in a similar fashion. Thick, viable, multi-layered tissue can be cultured for the desired amount of time (1-4 weeks).

and visualized via confocal laser scanning (Olympus FV3000 confocal microscope).

\section{RNA Isolation and Analyses}

Samples for RNA analysis were suspended in TRIZOL (Invitrogen) and homogenized. RNA extraction was completed using Direct-zolRNA MiniPrep Plus (Zymo Research Corporation) according to the manufacturer's protocol. Following concentration measurement on the Nanodrop device, $1 \mu \mathrm{g}$ of RNA was converted into complementary DNA (cDNA) through the reverse transcription reaction using the SuperScript IV VILO Master Mix (Thermo Fisher Scientific) then diluted to a final concentration of $5 \mathrm{ng} / \mu \mathrm{L}$. qPCR analysis of each sample was performed on a QuantStudio 3 real-time PCR system using PowerUp SYBR Green Master Mix (Thermo Fisher Scientific). Quantification of relative expression was done by normalizing to sample GAPDH expression. Primers used for RT-qPCR analysis are included in Supplementary Table 3.

\section{Optical Mapping}

To assess action potential duration (APD), CV, and minimum pacing cycle length, engineered $\mathrm{LbL}$ tissue samples were stained with a voltage-sensitive dye $\mathrm{RH}-237(2.5 \mu \mathrm{M})$ for $10 \mathrm{~min}$ and transferred to a perfusion chamber mounted on an inverted microscope. Control samples consisted of iCM:iEC bilayered tissue, while test samples consisted of iCM:iEC:cFBs. Samples were constantly perfused with Hank's balanced salt solution (HBSS) at approximately $37^{\circ} \mathrm{C}$. Pacing/stimulation of all samples was done with a bipolar electrode consisting of a glass pipette filled with HBSS and a silver wire coiled around its tip. A micromanipulator was used to position the electrode tip at the sample's edge. Rectangular stimulation pulses, with a duration of $2 \mathrm{~ms}$ and current strength 1.5-times the excitation threshold were used. Fluorescence was excited with a $200-W$ $\mathrm{Hg} / \mathrm{Xe}$ arc lamp and recorded with a $16 \times 16$ photodiode array (Hamamatsu) at a spatial resolution of $110 \mu \mathrm{m}$ per diode as previously described (Sowell and Fast, 2012). Excitation light was filtered at 532-587 nm, and emitted fluorescent light was filtered at $>650 \mathrm{~nm}$. The perfusion solution was supplemented with $5 \mu \mathrm{M}$ of blebbistatin to eliminate potential motion artifacts caused by the samples' spontaneous contractions. Isochronal maps of the activation spread were constructed from activation times measured at $50 \%$ of the maximum AP amplitude. CV was calculated at each recording site from local activation times and averaged across the whole mapping area. AP duration was measured at 50 and $80 \%$ of signal recovery $\left(\mathrm{APD}_{50}\right)$ and $\left(\mathrm{APD}_{80}\right)$, respectively.

\section{Statistical Analyses}

All results are reported as mean \pm standard error (mean \pm SEM). Significant differences between two mean values were determined via the Student's two-tailed $t$-test; and ANOVA or repeated ANOVA with the Tukey post hoc test were used for multiple (more than two groups) comparisons or repeated measurements. $p$-values of less than 0.05 were considered statistically significant. These analyses were performed utilizing GraphPad Prism8 data analysis software package.

\section{RESULTS}

\section{Layer-By-Layer Fabrication Produces Thick, Synchronously Beating, Fused Engineered Cardiac Tissue}

Engineered cardiac tissue produced with the optimized method described in Figure 1 yielded structures of $2.12 \pm 0.083$ and $1.38 \pm 0.019 \mathrm{~mm}$ in thickness after 1 and 4 weeks in culture, respectively (Figure $\mathbf{2 A}, n=4$ ). The statistically significant $(p<0.005)$ reduction in tissue thickness between week 1 and week 4 are most likely due to compaction caused by the contractile forces exerted by both the iCMs as well as the cFBs. Following the deposition of the iCMs, synchronization of the iCM layer in all samples was noted after $48 \mathrm{~h}$ (on Day 2). The resulting beating-rate (per min) of each engineered tissue was determined (Figure 2B), yielding a rate of $109 \pm 11.5$ beats/min (bpm). Following the iEC layer addition on Day 3 and an additional 2 days of culture (Day 5), the beating-rate on the fifth day of culture, prior to $\mathrm{cFB}$ deposition had decreased significantly, to $47 \pm 2.0 \mathrm{bpm}$. Following the deposition of the cFBs, and an additional $24 \mathrm{~h}$ of culture (Day 6), the beating-rate of the tissues was noted at $51 \pm 3.9 \mathrm{bpm}$. After 4 weeks in culture, the beating-rate of the constructs were noted at $55 \pm 1.8 \mathrm{bpm}$. 

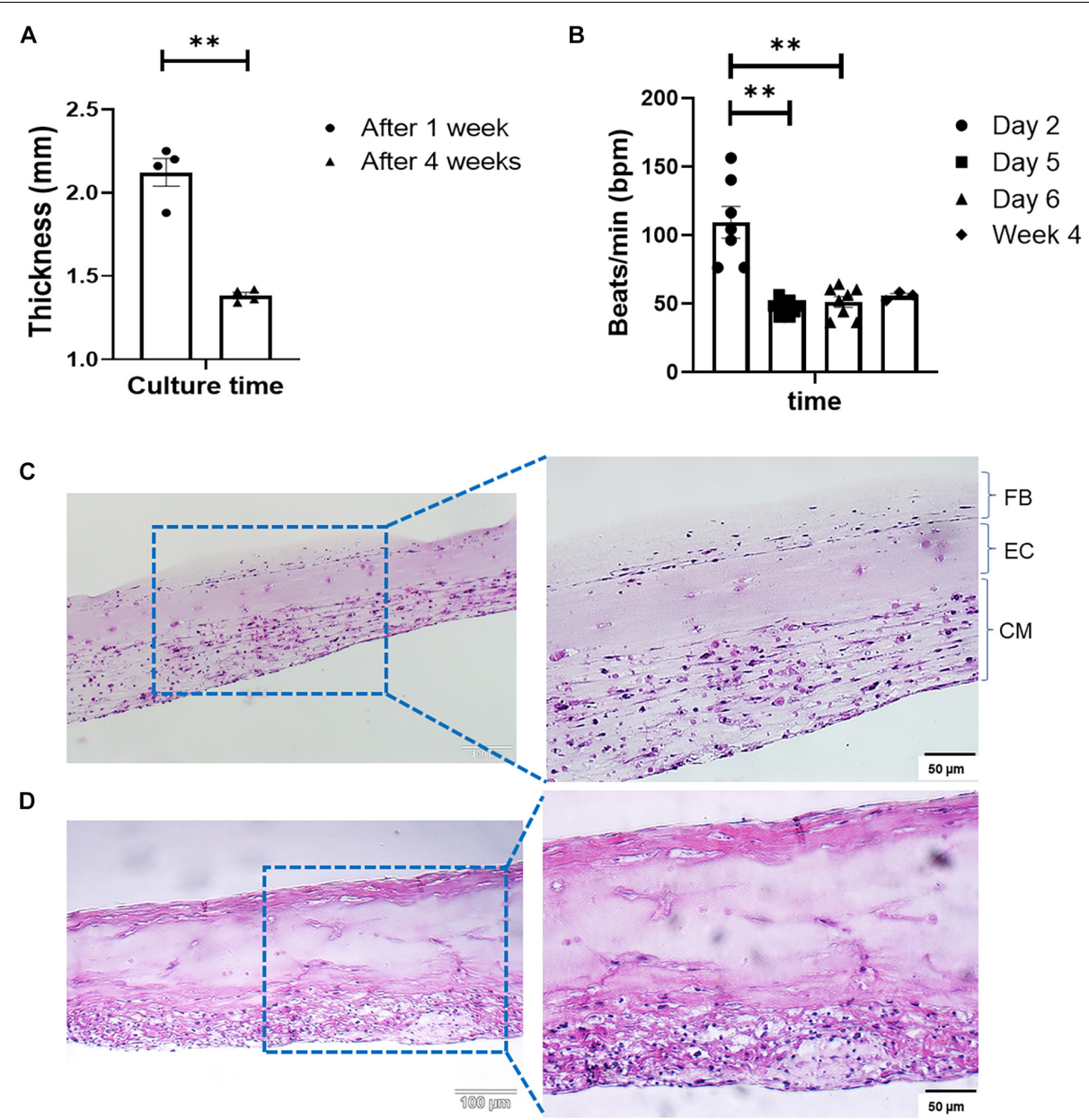

FIGURE 2 | (A) Change in tissue thickness between week 1 and week 4, measured with a caliper (Mitutoyo 500-196-30, Digimatic, $n=4$, $\left.{ }^{\star \star} p<0.005\right)$. (B) LbL engineered tissue beat-rate over the first 6 days of culture $(n=8)$ as well as week $4(n=3),{ }^{* *} p<0.005$. H\&E staining of LbL engineered tissue at (C) Day 7 , and (D) Day 28 of culturing.

Modification to the ECM composition between weeks 1 and 4 were observed via $\mathrm{H} \& \mathrm{E}$ staining (Figures 2C,D). Histology shows increases in structural ECM components such as collagen (increased intensity as well as the distribution of eosinophilic staining, Figures 2C,D). As sample time in culture increased, compaction of the structures the degree of compaction increased (Figure 2D), and structures, although initially somewhat disorganized (Figure 2C), began resembling in vivo muscle. The alterations in the ECM composition, specifically those associated with collagen deposition were attributed to both the culture of iCMs as well as the addition of cFBs, based on the strong eosinophilic staining noted in both the bottom as well as the top layers of the structure at week 4 (Figure 2D). Fusion and coupling of the structure layers was confirmed by not only the synchronous macroscopic beating of the engineered tissue (Figure 2B) but also via $\mathrm{H} \& \mathrm{E}$ staining. Another observation made via $\mathrm{H} \& \mathrm{E}$ was that of cell migration over the culture period. As with a previous study by this group (Pretorius et al., 2020), it was noted that iECs initiated migration and re-arrangement out of their originally deposited layer into the resident $\mathrm{ICM}$ layer within less than $48 \mathrm{~h}$ post-deposition, as is clear from the somewhat acellular appearance of the middle layer of the engineered tissue (Figure 2C). The degree of cell migration and potential iEC re-arrangement was confirmed with cell-specific immunofluorescent markers (Figure 4A). It should be noted that structures visualized here via H\&E staining appear thinner than those preserved in OCT or when measured with a caliper. This difference in overall tissue thickness is attributed to the multiple dehydration-related steps required during the $\mathrm{H} \& \mathrm{E}$ processing of the hydrogel structures leading to decreased preservation of the original architecture.

\section{Layer-By-Layer Fabrication Results in Engineered Tissue With Limited Necrosis Markers}

Tissue viability was determined via pMLKL staining (Figure 3), which specifically stains for cell necroptosis (Linkermann et al., 2014) and is associated with inflammatory markers (Negroni et al., 2017). The pMLKL-positive cells were quantified as 

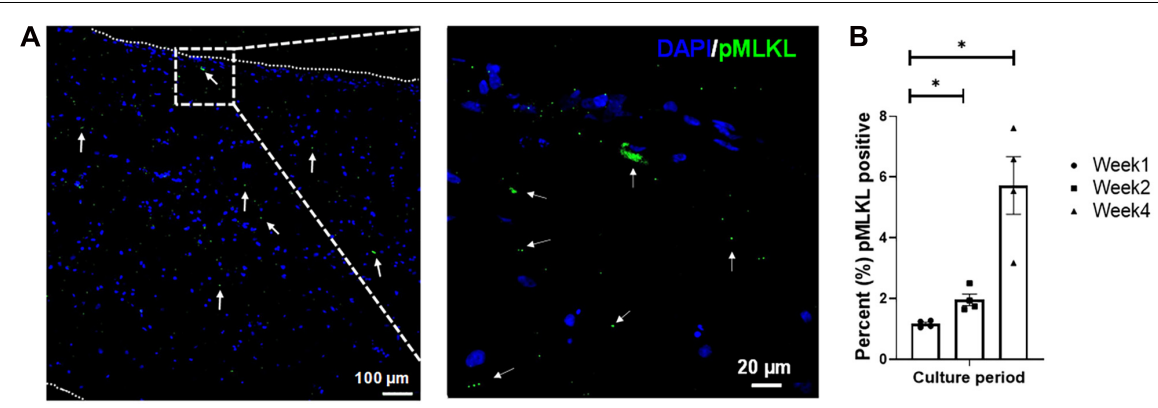

FIGURE 3 | Representative confocal micrograph of engineered LbL cardiac tissue displaying necrotic cells identified by the necrosis marker phosphorylated MLKL (Ser358, pMLKL) at (A) week 1 of culture, with $\mathbf{( B )}$ the percentage of necrotic cells in LbL engineered cardiac tissue $\left(n=4,{ }^{*} p<0.05\right)$. Border indicated with short dashed line.

a percentage (\%) of the total number of cells present (i.e., normalized to the DAPI staining, $n=4$ with a minimum of five images taken per sample). The initial degree of necrosis noted in the engineered tissues was very low, and quantified at $1.17 \pm 0.06 \%$. After an additional week of in vitro culture, the degree of necrosis increased to $1.96 \pm 0.19 \%$, while the degree of necrosis after 4 weeks in culture was observed to be $5.73 \pm 0.95 \%$. Even though the percentage of pMLKL positive cells increased significantly from week 1 to week 2 and week 4 , respectively, it still compared well with previously published data from our group, showing $5.6 \pm 1.4 \%$ after 4 weeks in culture of engineered structures that were initially $\sim 1.73 \mathrm{~mm}$ thick at week 1 (Pretorius et al., 2020).

\section{Cellular Migration and Fate}

Imaging of the fluorescently stained sections (Figure 4Ai) showed migration of the iECs as well as the cFBs toward their iCM counterparts within a number of days after these layers had been deposited. The migration process continued over the 4 weeks of culture, yet leaving no area of the engineered structure completely acellular (Figure 4Aii).

Expression levels of various cell markers were monitored over the culture period, i.e., cTnT for iCMs, CD31 for iECs as well as $\alpha$-SMA (alpha smooth muscle actin), periostin, vimentin and FAP (FB activation protein) for $\mathrm{cFBs}$ (Figure 4B). At each time point, at least three tissue samples were used to determine the respective expression levels. No statistically significant differences were noted in the expression levels of CD31, $\alpha$-SMA, periostin, and vimentin or FAP, suggesting that the expression levels of these factors were stable throughout the culturing period. The slight decrease noted in vimentin expression can potentially be attributed to senescence of the cFB line, which is known to occur in vitro after a specific number of cell divisions and/or passages (Zhang et al., 2019). The slight increases in factors such as periostin, rather, could potentially be suggestive of an environment that is conducive to cellular motility (Gillan et al., 2002). The only statistically significant difference was noted in the expression level of cTnT when comparing week 1 to week 4. This increase could more likely than not be attributed to the maturation of the iCMs in the engineered tissue, since iCMs are terminally differentiated cells and minimal proliferation is observed in these cell populations (see Supplementary Figure 2). To further investigate the potential maturation of the iCMs in the engineered tissues, the expression levels of known maturation markers as well as chamber-specific markers were examined (Figure 5).

Developmental and hormonal factors control the expression of alpha- and beta-myosin heavy chain (MHC), two functionally distinct, species-dependent cardiac MHC isoforms (Everett et al., 1984; Allen and Leinwand, 2001). Not only have these isoforms been shown to be correlated with contractile capabilities, but alterations in expression levels are also age-, and speciesdependent (van der Velden et al., 1998). Switches in expression from one isoform to another have been highly referenced in literature in developing systems, with increases in $\beta$-MHC and more specifically $\beta$-MHC: $\alpha \mathrm{MHC}$, being a key indicator of $\mathrm{CM}$ maturation (Reiser et al., 2001; Mihic et al., 2014; Yang et al., 2014; Ruan et al., 2015; LaBarge et al., 2019). During the culturing period, there was a statistically significant decrease in the expression levels of alpha-MHC ( $\alpha$-MHC), noted when comparing the expression levels of week 1 and week 2 as well as week 1 and week 4, respectively. Week 2 also saw an almost threefold increase $(p<0.05)$ in the expression level of betaMHC ( $\beta$-MHC) when compared to week 1 . Analysis of this ratio showed an eightfold increase from week 1 to week $2(p<0.05)$, and a 19-fold increase from week 1 to week $4(p<0.005)$.

Expression levels for chamber-specific markers, i.e., atrial (MLC2a) and ventricular (MLC2v), were also compared (Ng et al., 2010). Analysis showed no statistically significant differences in MLC2a or MLC2v between any of the time points. Interestingly enough, when comparing the expression levels of ventricular:atrial markers, i.e., MLC2v:MLC2a, a 2.7-fold increase $(p<0.05)$ was noted between week 1 and week 2 , while a 3.3 -fold increase $(p<0.005)$ was observed between week 1 and week 4 . With MI affecting the LV more prominently, having cells with a more ventricular-like phenotype present in the engineered tissues is highly advantageous.

\section{Dynamic ECM Evolution}

Throughout the 4-week culturing period, the engineered cardiac tissue structure ECM underwent remodeling to various degrees. As demonstrated in a previous study, due to fibrinolysis, 

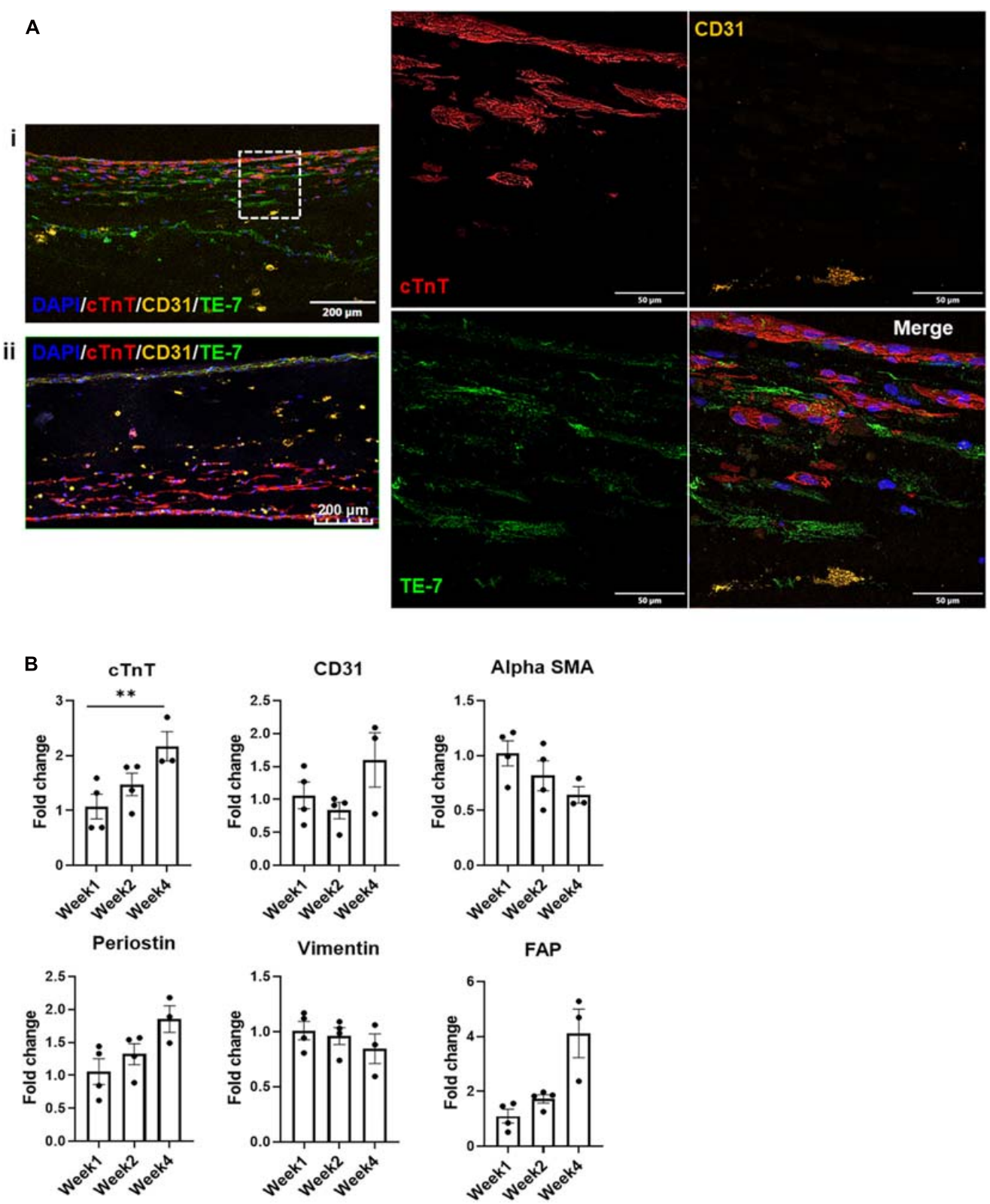

FIGURE 4 | (A) Fluorescent staining with cTnT, CD31, and TE-7 showing tri-lineage engineered tissue after (i) one and (ii) 4 weeks in culture, respectively, along with (B) expression levels of cell-specific markers at weeks one, two, and four, respectively $\left(n=4,{ }^{*} p<0.05,{ }^{* *} p<0.005\right)$.

the majority of the fibrin matrix degrades within the first 2 weeks (Pretorius et al., 2020) (see Supplementary Figure 3). For this study, the degree to which the remodeling occurs, and how the addition of the cFBs affected potential matrix deposition compared to our previous study, was monitored and expression levels quantified via RNA analysis. For this analysis, at least three tissue samples were used per time point. With knowledge obtained from prior studies regarding the ECM remodeling during the culturing of $\mathrm{iCMs}$ (Bax et al., 2012; Wendel et al., 2015; Pretorius et al., 2020), samples were again analyzed for additional ECM components, including collagen 1 (Col1), collagen 3 (Col3), collagen 4 (Col4), laminin (Lam), and fibronectin (FN) (Figure 6). Samples were also analyzed for elastin due to the incorporation of iECs and cFBs as well as the potential for vessel formation (Mecham et al., 1983; L'Heureux et al., 1998). Quantification showed a nearly fivefold increase in collagen 1 production from weeks 1 to 4 . This trend compared well with our previous studies, where bilayered structures consisting of only $\mathrm{iCMs}$ and $\mathrm{iECs}$ yielded a threefold increase in collagen 1 production (Pretorius et al., 2020). It is known that cFBs are vital in synthesizing ECM proteins, including, but not limited to, fibrillar collagen types 1 and 3, basement membrane type 4 collagen, FN, and laminin (Eghbali, 1992). Interestingly enough, the increasing trends in 

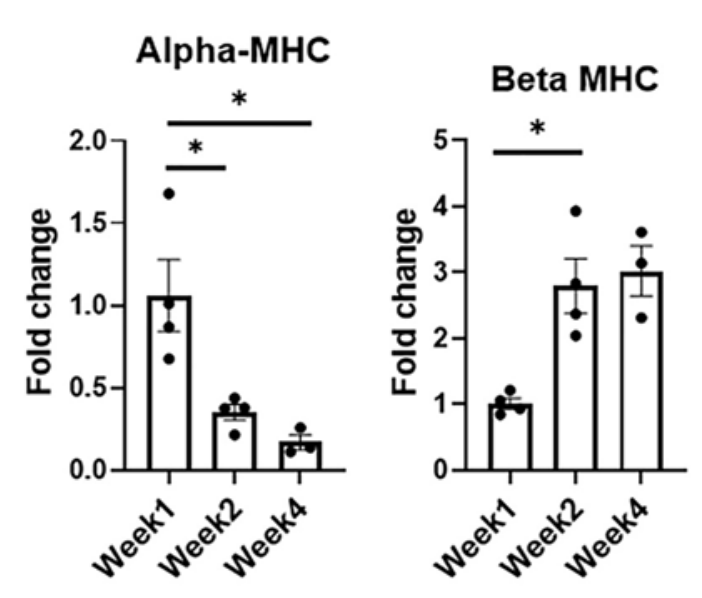

\section{Beta MHC/Alpha MHC}

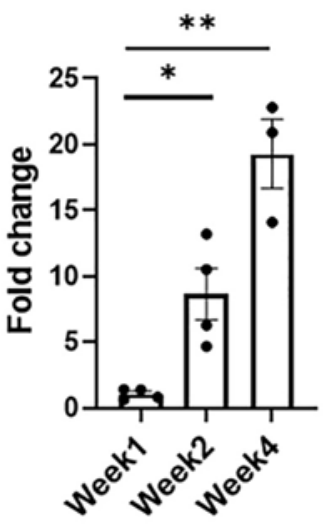

MLC2a

$$
\text { MLC2v }
$$
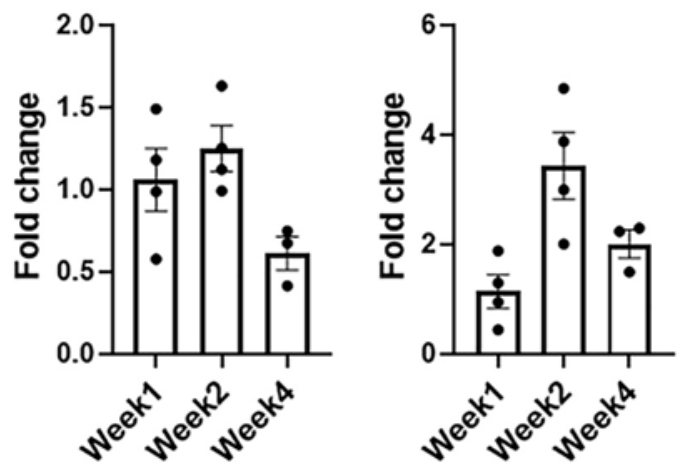

\section{MLC2v/MLC2a}

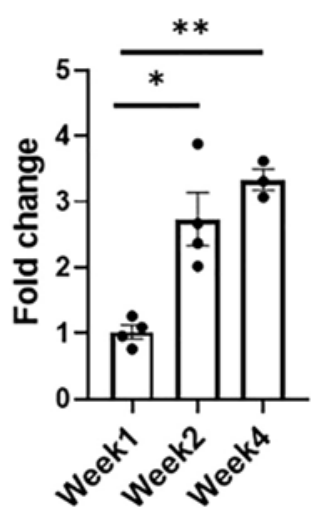

FIGURE 5 | Expression levels of CM-specific maturation and phenotypic markers at weeks one, two, and four, respectively $(n=4$ for week 1 and week $2, n=3$ for week $\left.4,{ }^{*} p<0.05,{ }^{* *} p<0.005\right)$.
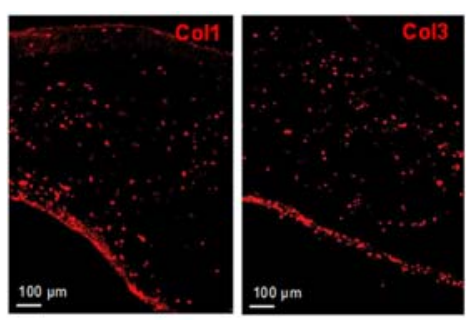

Collagen 3

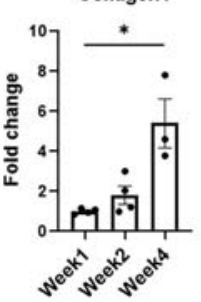

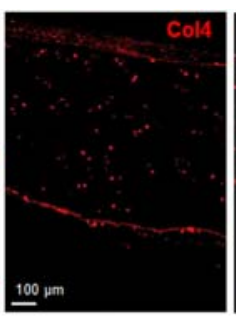

Collagen 4

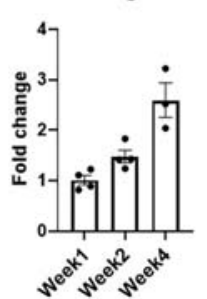

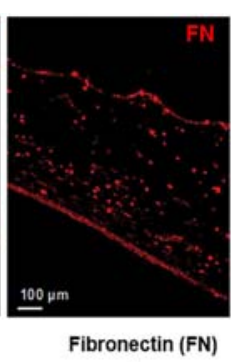
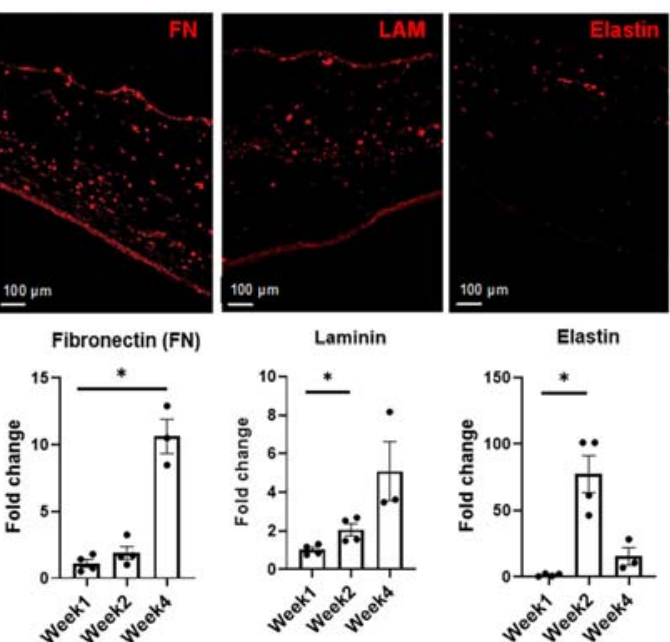

FIGURE 6 | Representative images and subsequent quantification of ECM evolution over 4 weeks in culture, showing the deposition of Collagen 1, Collagen 3 , Collagen 4, Fibronectin (FN), Laminin (LAM), and Elastin at week 4. Expression levels of each extracellular matrix (ECM) marker was determined via RNA analysis. Scale bars $=100 \mu \mathrm{m}, n=4$ for week 1 and week $2, n=3$ for week $4,{ }^{*} p<0.05,{ }^{\star *} p<0.005$. 
collagen 1 production were also associated with the upregulation trends in periostin (Figure 4B), a known proponent of collagen fibrillogenesis and ECM remodeling (Takayama et al., 2006; Norris et al., 2007). Similarly, there was an upregulation trend in the expression levels of FAP. Previous studies have shown that collagen induces FAP expression via binding of $\alpha 3 \beta 1$ integrin (Kennedy et al., 2009).

Statistically significant increases were observed in the expression levels of collagen 3 when comparing week 1 to week $2(p<0.005)$ and week 1 to week $4(p<0.05)$, respectively. Expression of collagen 4 levels increased at both week 2 and week 4 compared to week 1, though this increase was not statistically significant. An almost 10-fold increase in the expression level of FN was noted when comparing week 1 to week 4 . Statistically significant increases in the expression levels of laminin was noted between week 1 and week $2(p<0.05)$. An almost 70-fold increase in the expression level of elastin was observed from week 1 to week 2, followed by a decrease at week 4 . One potential cause of this sharp decrease in the elastin expression level could be linked to bFGF production by the iECs in the engineered constructs (Savchenko et al., 2019). Previous studies have shown that free bFGF decreases the expression levels of elastin at the transcriptional level in culture (Rich et al., 1996).

\section{Functional Performance of Tri-Lineage Engineered Tissue}

Expression levels of factors associated with functional performance were assessed by RNA analysis (Figure 7) of developmental transcription factor Tbx20, calcium handling machinery (JP2, RyR2, Cx43, SERCA, and CACNA1C) and optical mapping (Figure 8) to determine CVs through the tissue. All mapping was performed over the 4 week culture period. From week 1 to week 2 , there was a twofold increase in the expression level of RyR2, suggesting that some of the calcium handling machinery, specifically some of the machinery associated with sarcoplasmic reticulum (SR)-associated calcium release, improved (Ronaldson-Bouchard et al., 2018). A significant increase in Tbx20 expression was noted, with a 1.7-fold increase and a 2.5 -fold increase observed from week 1 to week 2 and week 1 to week 4 , respectively.

The conduction capabilities of the tri-lineage engineered cardiac tissues were evaluated over the 4 week period and compared to bilayered samples fabricated in a similar fashion, without any FBs (Figure 8). CVs were recorded between pacing cycle lengths of 200-800 ms, and average CVs are noted at the respective pacing cycle length in Figure 8A $(n=4$ for each time point). The average CV trends show that increased time in culture, i.e., 2 weeks vs. 1 week, and 4 weeks vs. 2 weeks, allows for enhanced conduction capabilities. This trend holds true over the entire pacing frequency range, up to $200 \mathrm{~ms}(5 \mathrm{~Hz})$. Maximum CVs noted at each time point, regardless of the pacing cycle length it was obtained at, are shown in Figure 8B. The maximum CV noted for each run was $25.6 \pm 2.47$ and $21.8 \pm 0.97 \mathrm{~cm} / \mathrm{s}$ for week $1,37.3 \pm 1.65$ and $36.8 \pm 2.59 \mathrm{~cm} / \mathrm{s}$ for week 2 , and $39.8 \pm 4.35$ and $30.0 \pm 1.36 \mathrm{~cm} / \mathrm{s}$ for week 4 , for the tri-lineage and bilayered cardiac tissue structures, respectively. Of particular note was that CVs as high as $49 \mathrm{~cm} / \mathrm{s}$ were obtained after 4 weeks in culture (Figure 8B). The tri-lineage structures showed significant increases in $\mathrm{CV}$ from week 1 to week 2, as well as week 1 to week 4, with an overall increasing trend. Bilayered structures also showed a significant increase in the $\mathrm{CV}$ when comparing values obtained at week 1 to week 2 , and week 1 to week 4 , but overall maximum CVs were obtained after 2 weeks in culture. Tri-lineage engineered tissue structure APD values were obtained as functions of pacing cycle length (Figure 8C). Isochronal activation maps show uniform signal propagation across the engineered cardiac tissue after 1 week of culture at pacing cycle lengths of 200 and $800 \mathrm{~ms}$ (Figure 8D). Isochronal activation maps of engineered tissues paced at weeks two and four also show uniform conduction (Supplementary Figure 4). The lack of observed conduction heterogeneity or conduction blocks suggests low arrhythmic risk of the constructs.

\section{DISCUSSION}

In this study, a modular LbL fabrication method was developed to fabricate cardiac muscle constructs from three cardiac cell types derived from human pluripotent stem cell lines. Over a 4 week period in culture, it was shown that these large and thick cardiac tissue constructs were functionally superior to previously reported engineered structures from the perspective of their larger, thicker nature, as well as superior APD CV. This study is the first to our knowledge to demonstrate robust $\left(1 \times 2 \mathrm{~cm}^{2}\right)$ hiPSC-derived engineered cardiac tissues that surpass $2 \mathrm{~mm}$ in thickness $(\sim 2.12 \mathrm{~mm})$, without significant apoptosis/necrosis. The physiologically relevant CVs ranging from around $25 \mathrm{~cm} / \mathrm{s}$ after 1 week in culture to velocities as high as $49 \mathrm{~cm} / \mathrm{s}$ after 4 weeks in culture, all lacking arrhythmogenic properties, demonstrate the significant clinical relevance of these cardiac muscle constructs. Previously, the best achievable thickness of engineered cardiac tissue constructs with this level of CV was only $100 \mu \mathrm{m}$ (Jackman et al., 2018). Quantification of the temporal stability of the expression of cTnT, CD31, $\alpha$-SMA, periostin, vimentin, and FAP suggested that all three cell populations (iCM, iEC, and $\mathrm{cFBs}$ ) were stable. Additionally, this study also considered the temporal changes that occur during ECM remodeling in these engineered tissues, via immunofluorescent staining and RNA expression levels.

We have recently reported (Gao et al., 2018) that a novel dynamically cultured engineered human cardiac muscle patch (hCMP) demonstrated a significant advancement in the field of myocardial tissue engineering, due to its clinically relevant dimensions ( $2 \mathrm{~cm} 4 \mathrm{~cm} \quad 1.2 \mathrm{~mm}$ ) as well as contractile force generation capabilities were substantially greater than had been previously achieved (Ruan et al., 2016; Shadrin et al., 2017; Yang and Murry, 2017). However, these hCMPs were manufactured by mixing hiPSC-CMs, -ECs, and -SMCs into a single layer of cells. In the functional myocardium, CMs are typically found adjacent to one another as opposed next to the SMCs, FBs or ECs, and the mixing of cardiac cells in engineered cardiac tissue likely preventing the hiPSC-CMs from coalescing into a fully interconnected contractile apparatus in the past. This might 

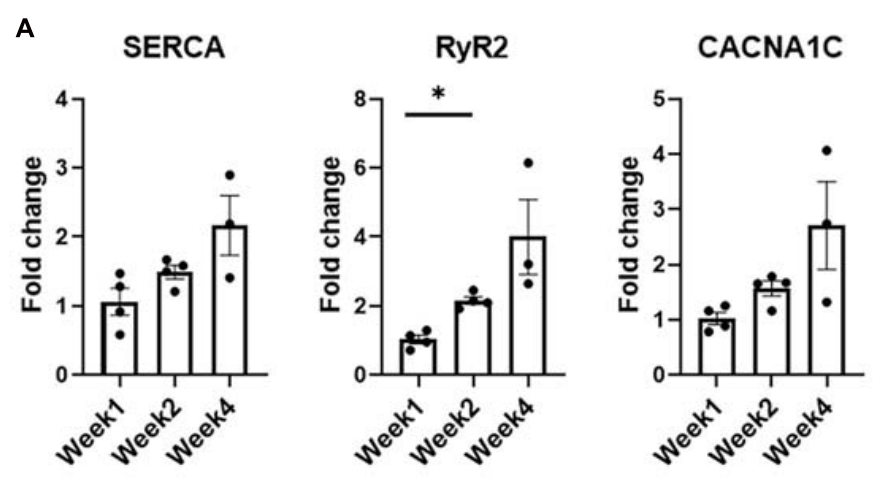

B

JP2-1

Cx43
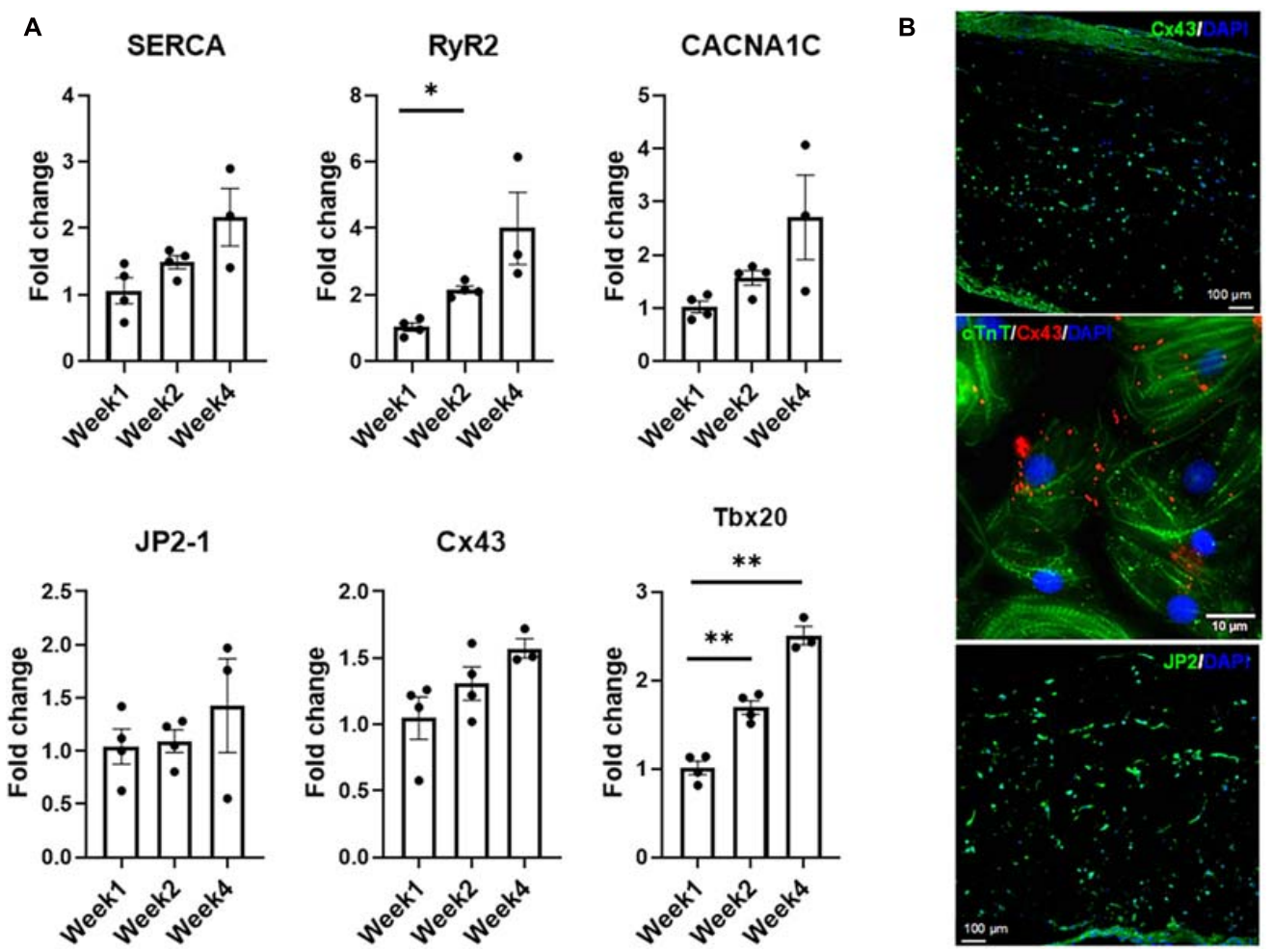

FIGURE 7 | (A) Expression levels of CM-specific functional markers at weeks one, two, and four, respectively ( $n=4$ for week 1 and week $2, n=3$ for week 4 , $\left.{ }^{*} p<0.05,{ }^{* *} p<0.005\right)$. (B) Representative confocal micrograph of tri-lineage engineered cardiac tissue at week 2 stained for Cx43 and JP2, respectively.
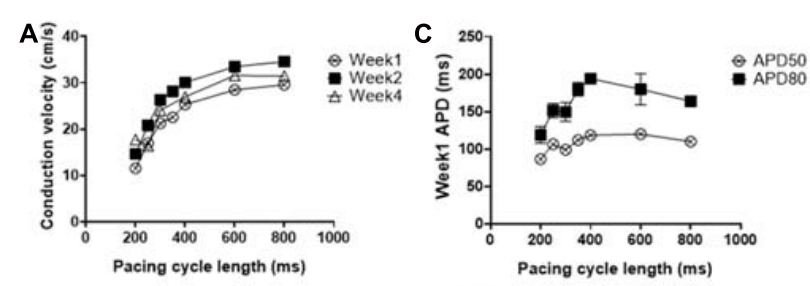

B
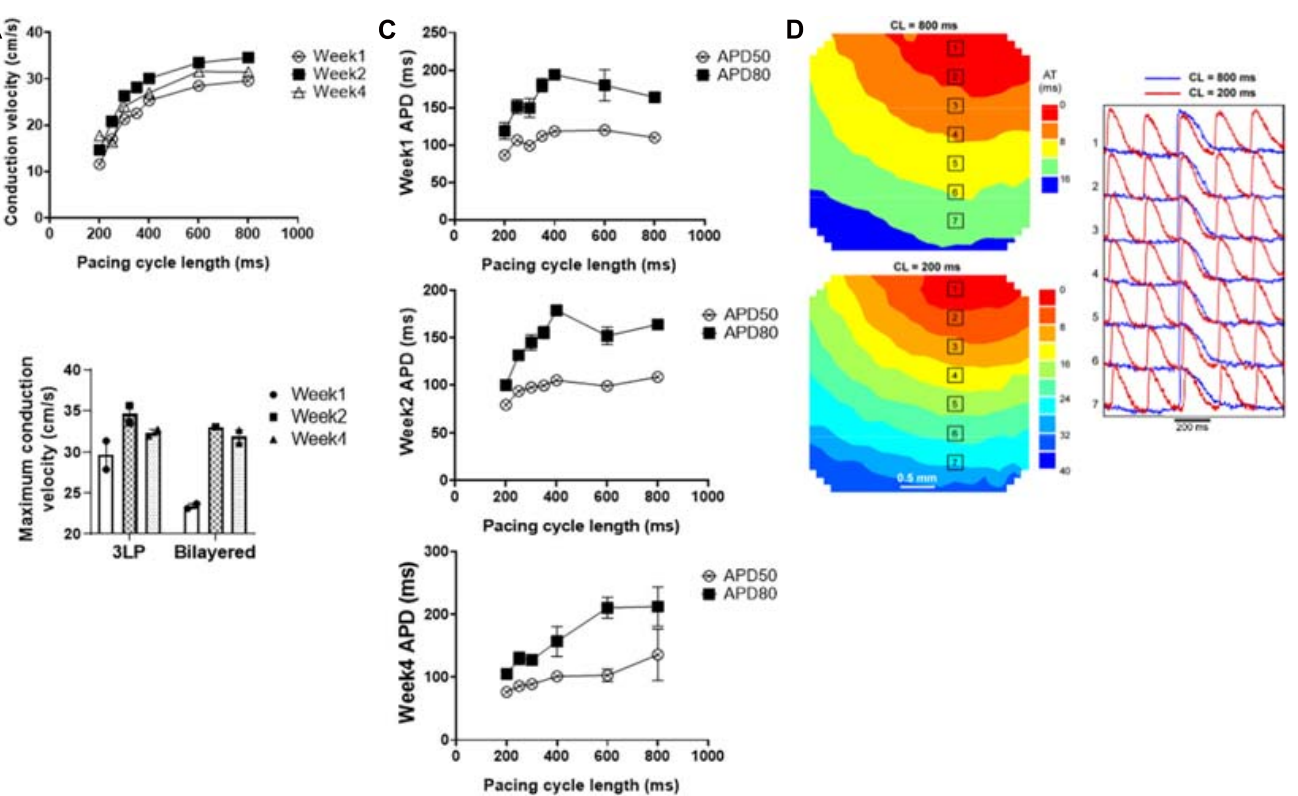

FIGURE 8 | Optical mapping results showing (A) the average conduction velocity of the tri-lineage engineered cardiac tissue at over the 4-week culture period as a function of pacing cycle length $(n=4)$, (B) the maximum conduction velocity of the tri-lineage engineered cardiac tissue compared to bilayered control engineered cardiac tissue, at each time point, respectively $\left(n=4\right.$ with $\left.{ }^{*} p<0.05\right)$, (C) $\mathrm{APD}_{50}$ and $\mathrm{APD}_{80}$ of the tri-lineage engineered cardiac tissue as a function of pacing cycle length $(n=4)$. (D) Representative isochronal electrical activation maps of engineered cardiac tissue, with representative optical action potentials at locations

indicated on maps pacing at $200 \mathrm{~ms}$ (red) and $800 \mathrm{~ms}$ (blue) cycle lengths after 1 week in culture. 
partially explain why force generation measurements remained lower than in native heart tissue. In the current study with an hCMP composed of layers of hiPSC-CMs, -ECs, and -FBs sandwiched in a LbL fashion, compared to a single layer of hiPSC$\mathrm{CMs}$, the three-layered patch generated approximately twice the $\mathrm{CV}$ compared to the previous study, suggesting a significantly improved physiology using this LbL approach.

Cardiac FBs are known to contribute significantly to the normal ECM formation. During the 4 weeks in culture, ECM remodeling occurs. The increases in collagen 3 (Figure 6) are likely a precursor to collagen 1 in this case, as it is known to play a vital role in collagen 1 fibrillogenesis and is crucial for normal cardiovascular development (Liu et al., 1997). Fibronectin, is highly expressed in the heart during the early stages of embryogenesis and has furthermore been shown to be vital in the vasculogenesis process (George et al., 1993). It has also been suggested that increases in FN expression, as noted at week 4 could be related to the regulation of vessel formation in similar engineered cardiac tissues (Pretorius et al., 2020). Even though laminin is known to be a basal lamina protein and more closely associated with cellular differentiation, migration and adhesion, it has been suggested that manipulation of the ECM laminin content may be an effective means of inducing structural and functional changes at a cellular level by altering the cardiac titin isoform ratio (Hochman-Mendez et al., 2020a). Laminins and other proteins are connected to the cell surface by costameres, which are in turn assembled by a combination of integrins and dystroglycans, and serve as a structural and functional bridge. These costameres and their subsequent integrins contribute to signal transduction, transmitting force signals between the contractile apparatus and ECM via interactions with primarily titin and other Z-line associated structures (Peter et al., 2011). This process not only supports the mechanical integrity of the sarcolemma, contributes to mechanical signaling but also provides spatial prompts for muscle fiber organization (Hochman-Mendez et al., $2020 \mathrm{~b})$. The upregulation in the levels of laminin observed in the tri-lineage tissues could, thus, likely be associated with the structural and functional maturation of the iCMs, as well as the enhanced tissue compaction and alignment noted in Figures 2C,D. Increases in periostin are associated with significant increases in elastin production by cardiac-specific cell, and more specifically those cells negative for CD31 and CD45 (Kanisicak et al., 2016). Furthermore, the increased expression of elastin could likely be attributed to cellular migration and rearrangement of the ECs into more organized structures as well (Mecham et al., 1983).

Even though the increases in junctophilin (JP2), sarco/endoplasmic reticulum $\mathrm{Ca}^{2+}$-ATPase (SERCA), calcium voltage-gated channel subunit alphal $\mathrm{C}$ (aka $\mathrm{Ca}_{v} 1.2$, encoded by CACNA1C) and connexin $43(\mathrm{Cx} 43)$ were not statistically significant, there were clear trends hinting at the development of the calcium handling machinery in the tri-lineage tissues (Figure 7). The multi-chambered mammalian heart has its origin from a simple tubual structure via polar elongation, myocardial differentiation and morphogenesis. The large family of T-box
(Tbx) transcription factors have been shown to be vital in their role as distinct subprograms during cardiac regionalization (Singh et al., 2005; Stennard et al., 2005). Tbx20 plays a central role in these pathways, and has important activities in both cardiac development and adult function, specifically affecting chamber differentiation and overexpression of Tbx20 has been shown to lead to increased expression of $\mathrm{Cx} 43$, and subsequent increases in CVs in vivo (Chakraborty and Yutzey, 2012). The expression of Tbx20 has also been associated with the activation of and maturation-associated genes in iCMs such as those recorded in Figure 5 (Zhou et al., 2020). The tri-lineage $\mathrm{LbL}$ cardiac engineered tissues fabricated here are the first, to our knowledge, to be fabricated from hiPSC-CMs that have not only generated physiologically relevant CVs in excess of $30 \mathrm{~cm} / \mathrm{s}$ (Yang et al., 2014), but generated velocities close to $50 \mathrm{~cm} / \mathrm{s}$ with these cells (Figure 8B). Whether this increase in structure functionality is a function of cell-cell communication and paracrine signaling, a function of increased culturing time, or a combination of these factors remains to be seen. It has been shown, however, that cFBs do affect the maturation of hiPSC-CMs through secretion of growth-related cytokines when co-cultured (Ieda et al., 2009). These data suggest that superior electrophysiological function of the current LbL approach may be in part caused by the addition of the cFB layer.

It should be noted that, even though this $3 \mathrm{D}$ in vitro study enhanced our knowledge-base of thick, engineered cardiac tissue structures and some of their electrophysiological capabilities, further studies are required to better understand the mechanical aspects of the system. In order to better understand, model future system and avoid mechanical mismatch when implanting these structures, their viscoelastic properties need to be determined and related to the dynamic properties of the ECM (Little and Wead, 1971; Tsaturyan et al., 1984; Miller and Wong, 2000; Wang et al., 2010).

\section{CONCLUSION}

Here we have shown that a modular fabrication method, like LbL assembly, can be utilized to produce thick $(\sim 2.12 \mathrm{~mm})$, viable engineered cardiac tissues from hiPSCs. The incorporation of cardiac FBs into the LbL assembly method allowed for superior, previously unobtainable $\mathrm{CVs}(>30 \mathrm{~cm} / \mathrm{s})$ along with a lack in arrhythmogenic potential, with tissues having the ability to be paced to $5 \mathrm{~Hz}(200 \mathrm{~ms})$. In vitro characterization showed engineered tissue structures resembling those of native cardiac tissue along with minimal necrosis, even after 4 weeks in culture. Considering that the tissues engineered for this study have not undergone any form of maturation, nor have they been exposed to any external stimuli, suggests that their performance capabilities could be enhanced even further.

Future work will include the mechanical testing of the engineered cardiac tissues to determine viscoelastic properties to ultimately prevent mechanical mismatch between the engineered tissues and future host. In vivo studies in a large animal model will also commence in order to assess the potential clinical application 
of these larger, thicker, engineered cardiac tissues in preventing LV dilatation of hearts with postinfarction LV remodeling.

\section{DATA AVAILABILITY STATEMENT}

The raw data generated for this study are available on request to the corresponding author.

\section{AUTHOR CONTRIBUTIONS}

DP designed the LbL fabrication technique, designed the experiments, performed histology and imaging, sample preparation, and wrote the manuscript. AK-K performed the cell differentiation, sample staining, and imaging as well as RNA analysis. XL performed the cell differentiation, sample staining, and imaging. VF performed the optical mapping. JB reviewed the manuscript. TK supplied $\mathrm{cFBs}$ and reviewed the manuscript. JZ provided the project leadership, funding acquisition, method development, and manuscript revisions.

\section{REFERENCES}

Allen, D. L., and Leinwand, L. A. (2001). Postnatal myosin heavy chain isoform expression in normal mice and mice null for iib or iid myosin heavy chains. Dev. Biol. 229, 383-395. doi: 10.1006/dbio.2000.9974

Bax, N. A. M., Van Marion, M. H., Shah, B., Goumans, M.-J., Bouten, C. V. C., and Van Der Schaft, D. W. J. (2012). Matrix production and remodeling capacity of cardiomyocyte progenitor cells during in vitro differentiation. J. Mol. Cell. Cardiol. 53, 497-508. doi: 10.1016/j.yjmcc.2012.07.003

Burridge, P. W., Matsa, E., Shukla, P., Lin, Z. C., Churko, J. M., Ebert, A. D., et al. (2014). Chemically defined generation of human cardiomyocytes. Nat. Methods 11, 855-860. doi: 10.1038/nmeth.2999

Chakraborty, S., and Yutzey, K. E. (2012). Tbx20 regulation of cardiac cell proliferation and lineage specialization during embryonic and fetal development in vivo. Dev. Biol. 363, 234-246. doi: 10.1016/j.ydbio.2011.12.034

Eghbali, M. (1992). Cardiac fibroblasts: function, regulation of gene expression, and phenotypic modulation. Basic Res. Cardiol. 87(Suppl. 2), 183-189. doi: 10.1007/978-3-642-72477-0_16

Everett, A. W., Sinha, A. M., Umeda, P. K., Jakovcic, S., Rabinowitz, M., and Zak, R. (1984). Regulation of myosin synthesis by thyroid hormone: relative change in the alpha-and beta-myosin heavy chain mRNA levels in rabbit heart. Biochemistry 23, 1596-1599. doi: 10.1021/bi0030 $3 \mathrm{a} 002$

Gao, L., Gregorich, Z. R., Zhu, W., Mattapally, S., Oduk, Y., Lou, X., et al. (2018). Large cardiac muscle patches engineered from human induced-pluripotent stem cell-derived cardiac cells improve recovery from myocardial infarction in swine. Circulation 137, 1712-1730. doi: 10.1161/circulationaha.117.030785

Gao, L., Kupfer, M. E., Jung, J. P., Yang, L., Zhang, P., Sie, Y. D., et al. (2017). Myocardial tissue engineering with cells derived from human-induced pluripotent stem cells and a native-like, high-resolution, 3-dimensionally printed scaffold. Circ. Res. 120, 1318-1325. doi: 10.1161/circresaha.116.310277

George, E. L., Georges-Labouesse, E. N., Patel-King, R. S., Rayburn, H., and Hynes, R. O. (1993). Defects in mesoderm, neural tube and vascular development in mouse embryos lacking fibronectin. Development 119, 1079-1091.

Gillan, L., Matei, D., Fishman, D. A., Gerbin, C. S., Karlan, B. Y., and Chang, D. D. (2002). Periostin secreted by epithelial ovarian carcinoma is a ligand for alpha(V)beta(3) and alpha(V)beta(5) integrins and promotes cell motility. Cancer Res. 62, 5358-5364.

Gorenek, B., Blomström Lundqvist, C., Brugada Terradellas, J., Camm, A. J., Hindricks, G., Huber, K., et al. (2014). Cardiac arrhythmias in acute coronary
All authors contributed to the article and approved the submitted version.

\section{FUNDING}

This study was supported in part by the National Institutes of Health (NIH) NHLBI grants RO1 HL114120, HL131017, HL149137, UO1 HL134764, and NIH BIB T32 EB023872.

\section{ACKNOWLEDGMENTS}

The authors would like to thank UAB Pathology Core Lab for their assistance with sample preparation.

\section{SUPPLEMENTARY MATERIAL}

The Supplementary Material for this article can be found online at: https://www.frontiersin.org/articles/10.3389/fcell.2021. 670504/full\#supplementary-material

syndromes: position paper from the joint EHRA, ACCA, and EAPCI task force. Eurointervention 16, 1655-1673. doi: 10.1093/europace/euu208

Henkel, D. M., Witt, B. J., Gersh, B. J., Jacobsen, S. J., Weston, S. A., Meverden, R. A., et al. (2006). Ventricular arrhythmias after acute myocardial infarction: a 20-year community study. Am. Heart J. 151, 806-812. doi: 10.1016/j.ahj.2005. 05.015

Hochman-Mendez, C., Curty, E., and Taylor, D. A. (2020a). Change the laminin, change the cardiomyocyte: improve untreatable heart failure. Int. J. Mol. Sci. 21:6013. doi: 10.3390/ijms21176013

Hochman-Mendez, C., Pereira De Campos, D. B., Pinto, R. S., Mendes, B., Rocha, G. M., Monnerat, G., et al. (2020b). Tissue-engineered human embryonic stem cell-containing cardiac patches: evaluating recellularization of decellularized matrix. J. Tissue Eng. 11:2041731420921482.

Ieda, M., Tsuchihashi, T., Ivey, K. N., Ross, R. S., Hong, T. T., Shaw, R. M., et al. (2009). Cardiac fibroblasts regulate myocardial proliferation through beta1 integrin signaling. Dev. Cell 16, 233-244. doi: 10.1016/j.devcel.2008.12.007

Jackman, C. P., Ganapathi, A. M., Asfour, H., Qian, Y., Allen, B. W., Li, Y., et al. (2018). Engineered cardiac tissue patch maintains structural and electrical properties after epicardial implantation. Biomaterials 159, 48-58. doi: 10.1016/ j.biomaterials.2018.01.002

Kanisicak, O., Khalil, H., Ivey, M. J., Karch, J., Maliken, B. D., Correll, R. N., et al. (2016). Genetic lineage tracing defines myofibroblast origin and function in the injured heart. Nat. Commun. 7:12260.

Kennedy, A., Dong, H., Chen, D., and Chen, W. T. (2009). Elevation of seprase expression and promotion of an invasive phenotype by collagenous matrices in ovarian tumor cells. Int. J. Cancer 124, 27-35. doi: 10.1002/ijc.23871

LaBarge, W., Mattappally, S., Kannappan, R., Fast, V. G., Pretorius, D., Berry, J. L., et al. (2019). Maturation of three-dimensional, hiPSC-derived cardiomyocyte spheroids utilizing cyclic, uniaxial stretch and electrical stimulation. PLoS One 14:e0219442. doi: 10.1371/journal.pone.0219442

Lake, C. L., Sellers, T. D., Crosby, I. K., Wellons, H. A., and Crampton, R. S. (1985). Effects of coronary grafting technique upon reperfusion cardiac rhythm, ventricular function, and other variables. Am. Surg. 51, 497-503.

Lee, P., Klos, M., Bollensdorff, C., Hou, L., Ewart, P., Kamp, T. J., et al. (2012). Simultaneous voltage and calcium mapping of genetically purified human induced pluripotent stem cell-derived cardiac myocyte monolayers. Circ. Res. 110, 1556-1563. doi: 10.1161/circresaha.111.262535

L'Heureux, N., Pâquet, S., Labbé, R., Germain, L., and Auger, F. A. (1998). A completely biological tissue-engineered human blood vessel. FASEB J. 12, 47-56. doi: 10.1096/fsb2fasebj.12.1.47 
Li, W., Germain, R. N., and Gerner, M. Y. (2019). High-dimensional cell-level analysis of tissues with Ce3D multiplex volume imaging. Nat. Protoc. 14, 1708-1733. doi: 10.1038/s41596-019-0156-4

Lian, X., Zhang, J., Azarin, S. M., Zhu, K., Hazeltine, L. B., Bao, X., et al. (2012). Directed cardiomyocyte differentiation from human pluripotent stem cells by modulating Wnt/ $\beta$-catenin signaling under fully defined conditions. Nat. Protoc. 8:162. doi: 10.1038/nprot.2012.150

Linkermann, A., Kunzendorf, U., and Krautwald, S. (2014). Phosphorylated MLKL causes plasma membrane rupture. Mol. Cell. Oncol. 1:e29915. doi: 10.4161/ mco. 29915

Little, R., and Wead, W. (1971). Diastolic viscoelastic properties of active and quiescent cardiac muscle. Am. J. Physiol. 221, 1120-1125. doi: 10.1152/ ajplegacy.1971.221.4.1120

Liu, J., Laksman, Z., and Backx, P. H. (2016). The electrophysiological development of cardiomyocytes. Adv. Drug Deliv. Rev. 96, 253-273. doi: 10.1016/j.addr.2015. 12.023

Liu, X., Wu, H., Byrne, M., Krane, S., and Jaenisch, R. (1997). Type III collagen is crucial for collagen I fibrillogenesis and for normal cardiovascular development. Proc. Natl. Acad. Sci.U.S.A. 94, 1852-1856. doi: 10.1073/pnas.94.5.1852

Lucas, D. T., and Szweda, L. I. (1999). Declines in mitochondrial respiration during cardiac reperfusion: age-dependent inactivation of $\alpha$-ketoglutarate dehydrogenase. Proc. Natl. Acad. Sci. U.S.A. 96, 6689-6693. doi: 10.1073/pnas. 96.12.6689

Mecham, R. P., Madaras, J., Mcdonald, J. A., and Ryan, U. (1983). Elastin production by cultured calf pulmonary artery endothelial cells. J. Cell. Physiol. 116, 282-288. doi: 10.1002/jcp.1041160304

Mihic, A., Li, J., Miyagi, Y., Gagliardi, M., Li, S.-H., Zu, J., et al. (2014). The effect of cyclic stretch on maturation and 3D tissue formation of human embryonic stem cell-derived cardiomyocytes. Biomaterials 35, 2798-2808. doi: 10.1016/j. biomaterials.2013.12.052

Miller, C. E., and Wong, C. L. (2000). Trabeculated embryonic myocardium shows rapid stress relaxation and non-quasi-linear viscoelastic behavior. J. Biomech. 33, 615-622. doi: 10.1016/s0021-9290(99)00212-2

Mummery, C. L., Zhang, J., Ng, E. S., Elliott, D. A., Elefanty, A. G., and Kamp, T. J. (2012). Differentiation of human embryonic stem cells and induced pluripotent stem cells to cardiomyocytes. Circ. Res. 111, 344-358.

Murphy, E., and Steenbergen, C. (2008). Mechanisms underlying acute protection from cardiac ischemia-reperfusion injury. Physiol. Rev. 88, 581-609. doi: 10. 1152/physrev.00024.2007

Negroni, A., Colantoni, E., Pierdomenico, M., Palone, F., Costanzo, M., Oliva, S., et al. (2017). RIP3 AND pMLKL promote necroptosis-induced inflammation and alter membrane permeability in intestinal epithelial cells. Dig. Liver Dis. 49, 1201-1210. doi: 10.1016/j.dld.2017.08.017

Ng, S. Y., Wong, C. K., and Tsang, S. Y. (2010). Differential gene expressions in atrial and ventricular myocytes: insights into the road of applying embryonic stem cell-derived cardiomyocytes for future therapies. Am. J. Physiol. Cell Physiol. 299, C1234-C1249.

Norris, R. A., Damon, B., Mironov, V., Kasyanov, V., Ramamurthi, A., MorenoRodriguez, R., et al. (2007). Periostin regulates collagen fibrillogenesis and the biomechanical properties of connective tissues. J. Cell. Biochem. 101, 695-711. doi: $10.1002 /$ jcb. 21224

O'Hara, T., Virág, L., Varró, A., and Rudy, Y. (2011). Simulation of the undiseased human cardiac ventricular action potential: model formulation and experimental validation. PLoS Comput. Biol. 7:e1002061. doi: 10.1371/journal. pcbi. 1002061

Peter, A. K., Cheng, H., Ross, R. S., Knowlton, K. U., and Chen, J. (2011). The costamere bridges sarcomeres to the sarcolemma in striated muscle. Prog. Pediatr. Cardiol. 31, 83-88. doi: 10.1016/j.ppedcard.2011.02.003

Pinto, A. R., Ilinykh, A., Ivey, M. J., Kuwabara, J. T., D’antoni, M. L., Debuque, R., et al. (2016). Revisiting cardiac cellular composition. Circ. Res. 118, 400-409. doi: 10.1161/circresaha.115.307778

Pretorius, D., Kahn-Krell, A. M., Labarge, W. C., Lou, X., Kannappan, R., Pollard, A. E., et al. (2020). Fabrication and characterization of a thick, viable bi-layered stem cell-derived surrogate for future myocardial tissue regeneration. Biomed. Mater. 16:035007. doi: 10.1088/1748-605x/abc107

Reiser, P. J., Portman, M. A., Ning, X.-H., and Moravec, C. S. (2001). Human cardiac myosin heavy chain isoforms in fetal and failing adult atria and ventricles. Am. J. Physiol. Heart Circ. Physiol. 280, H1814-H1820.
Rich, C. B., Nugent, M. A., Stone, P., and Foster, J. A. (1996). Elastase release of basic fibroblast growth factor in pulmonary fibroblast cultures results in downregulation of elastin gene transcription: a role for basic fibroblast growth factor in regulating lung repair. J. Biol. Chem. 271, 23043-23048. doi: 10.1074/jbc.271. 38.23043

Ronaldson-Bouchard, K., Ma, S. P., Yeager, K., Chen, T., Song, L., Sirabella, D., et al. (2018). Advanced maturation of human cardiac tissue grown from pluripotent stem cells. Nature 556, 239-243. doi: 10.1038/s41586-018-0016-3

Ruan, J. L., Tulloch, N. L., Razumova, M. V., Saiget, M., Muskheli, V., Pabon, L., et al. (2016). Mechanical stress conditioning and electrical stimulation promote contractility and force maturation of induced pluripotent stem cell-derived human cardiac tissue. Circulation 134, 1557-1567. doi: 10.1161/circulationaha. 114.014998

Ruan, J.-L., Tulloch, N. L., Saiget, M., Paige, S. L., Razumova, M. V., Regnier, M., et al. (2015). Mechanical stress promotes maturation of human myocardium from pluripotent stem cell-derived progenitors. Stem Cells 33, 2148-2157. doi: 10.1002/stem.2036

Savchenko, E., Teku, G. N., Boza-Serrano, A., Russ, K., Berns, M., Deierborg, T., et al. (2019). FGF family members differentially regulate maturation and proliferation of stem cell-derived astrocytes. Sci. Rep. 9:9610.

Shadrin, I. Y., Allen, B. W., Qian, Y., Jackman, C. P., Carlson, A. L., Juhas, M. E., et al. (2017). Cardiopatch platform enables maturation and scale-up of human pluripotent stem cell-derived engineered heart tissues. Nat. Commun. 8:1825.

Singh, M. K., Christoffels, V. M., Dias, J. M., Trowe, M. O., Petry, M., SchusterGossler, K., et al. (2005). Tbx20 is essential for cardiac chamber differentiation and repression of Tbx2. Development 132, 2697-2707. doi: 10.1242/dev.01854

Sowell, B., and Fast, V. G. (2012). Ionic mechanism of shock-induced arrhythmias: role of intracellular calcium. Heart Rhythm 9, 96-104. doi: 10.1016/j.hrthm. 2011.08.024

Stennard, F. A., Costa, M. W., Lai, D., Biben, C., Furtado, M. B., Solloway, M. J., et al. (2005). Murine T-box transcription factor Tbx20 acts as a repressor during heart development, and is essential for adult heart integrity, function and adaptation. Development 132, 2451-2462. doi: 10.1242/dev.01799

Su, L., Kong, X., Lim, S., Loo, S., Tan, S., Poh, K., et al. (2018). The prostaglandin H2 analog U-46619 improves the differentiation efficiency of human induced pluripotent stem cells into endothelial cells by activating both p38MAPK and ERK1/2 signaling pathways. Stem Cell Res. Ther. 9:313.

Takayama, G., Arima, K., Kanaji, T., Toda, S., Tanaka, H., Shoji, S., et al. (2006). Periostin: a novel component of subepithelial fibrosis of bronchial asthma downstream of IL-4 and IL-13 signals. J. Allergy Clin. Immunol. 118, 98-104. doi: 10.1016/j.jaci.2006.02.046

Tsaturyan, A. K., Izacov, V. J., Zhelamsky, S. V., and Bykov, B. L. (1984). Extracellular fluid filtration as the reason for the viscoelastic behaviour of the passive myocardium. J. Biomech. 17, 749-755. doi: 10.1016/0021-9290(84) 90105-2

Valderrábano, M. (2007). Influence of anisotropic conduction properties in the propagation of the cardiac action potential. Prog. Biophys. Mol. Biol. 94, 144168. doi: 10.1016/j.pbiomolbio.2007.03.014

van der Velden, J., Moorman, A. F., and Stienen, G. J. (1998). Age-dependent changes in myosin composition correlate with enhanced economy of contraction in guinea-pig hearts. J. Physiol. 507(Pt 2), 497-510. doi: 10.1111/ j.1469-7793.1998.497bt.x

Wang, B., Borazjani, A., Tahai, M., Curry, A. L., Simionescu, D. T., Guan, J., et al. (2010). Fabrication of cardiac patch with decellularized porcine myocardial scaffold and bone marrow mononuclear cells. J. Biomed. Mater. Res. A 94, $1100-1110$.

Wendel, J. S., Ye, L., Tao, R., Zhang, J., Zhang, J., Kamp, T. J., et al. (2015). Functional effects of a tissue-engineered cardiac patch from human induced pluripotent stem cell-derived cardiomyocytes in a rat infarct model. Stem Cells Transl. Med. 4, 1324-1332. doi: 10.5966/sctm.2015-0044

Xiaojun, L., Cheston, H., Gisela, W., Kexian, Z., Laurie, B. H., Samira, M. A., et al. (2012). Robust cardiomyocyte differentiation from human pluripotent stem cells via temporal modulation of canonical Wnt signaling. Proc. Natl. Acad. Sci. U.S.A. 109, E1848-E1857.

Xiaojun, L., Xiaoping, B., Abraham, A.-A., Jialu, L., Yue, W., Wentao, D., et al. (2014). Efficient differentiation of human pluripotent stem cells to endothelial progenitors via small-molecule activation of WNT signaling. Stem Cell Rep. 3, 804-816. doi: 10.1016/j.stemcr.2014.09.005 
Yang, X., and Murry, C. E. (2017). One stride forward: maturation and scalable production of engineered human myocardium. Circulation 135, 1848-1850. doi: 10.1161/circulationaha.117.024751

Yang, X., Pabon, L., and Murry, C. E. (2014). Engineering adolescence. Circ. Res. 114, 511-523.

Ye, L., Chang, Y. H., Xiong, Q., Zhang, P., Zhang, L., Somasundaram, P., et al. (2014). Cardiac repair in a porcine model of acute myocardial infarction with human induced pluripotent stem cell-derived cardiovascular cells. Cell Stem Cell 15, 750-761. doi: 10.1016/j.stem.2014.11.009

Zhang, J., Tao, R., Campbell, K. F., Carvalho, J. L., Ruiz, E. C., Kim, G. C., et al. (2019). Functional cardiac fibroblasts derived from human pluripotent stem cells via second heart field progenitors. Nat. Commun. 10:2238.

Zhang, S., Dutton, J. R., Su, L., Zhang, J., and Ye, L. (2014). The influence of a spatiotemporal 3D environment on endothelial cell differentiation of human induced pluripotent stem cells. Biomaterials 35, 3786-3793. doi: 10.1016/j. biomaterials.2014.01.037

Zhou, Y., Tang, Y., Fast, V. G., Zhao, L., Lu, R., and Zhang, J. (2020). Abstract 103: TBX20 activates cardiac maturation gene programs promoting direct human cardiac reprogramming. Circ. Res. 127, A103-A103.

Zhu, W., Gao, L., and Zhang, J. (2017). Pluripotent stem cell derived cardiac cells for myocardial repair. J. Vis. Exp. 120, e55142.

Conflict of Interest: TK is a consultant for Fujifilm CDI.

The remaining authors declare that the research was conducted in the absence of any commercial or financial relationships that could be construed as a potential conflict of interest.

Copyright (c) 2021 Pretorius, Kahn-Krell, Lou, Fast, Berry, Kamp and Zhang. This is an open-access article distributed under the terms of the Creative Commons Attribution License (CC BY). The use, distribution or reproduction in other forums is permitted, provided the original author(s) and the copyright owner(s) are credited and that the original publication in this journal is cited, in accordance with accepted academic practice. No use, distribution or reproduction is permitted which does not comply with these terms. 